Acta vet. scand. $1978,19,607-608$.

Brief Communication

\title{
RECOVERY OF TRICHINELLA SPIRALIS LARVAE FROM FROZEN MUSCLE SAMPLES
}

Demonstration of Trichinella spiralis in suspensions of digested muscle tissue has until now mainly been based on methods utilizing the coiling and/or the motility of the living larvae. Considering this, Jackson (1977) estimated that, compared to the number observed by examination of corresponding unfrozen samples, $78 \%$ of larvae in frozen samples would be lost, when an ordinary pepsin- $\mathrm{HCl}$ digestion technique was used.

A technique implying ether extraction and developed specifically for demonstration of dead (frozen) larvae, has been described from the USA (Dyer \& Evje 1971). The technique seems, on an average, to offer a recovery rate of $80 \%$ of dead larvae added to digested suspensions.

The following experiments were designed to show, if T. spiralis larvae could be demonstrated in frozen samples of muscle tissue by a technique based on observation of larvae retained and subsequently stained on disposable sieves (Henriksen 1978).

T a ble 1. Number of larvae of Trichinella spiralis observed by examination of $25 \mathrm{~g}$ muscle tissue.

\begin{tabular}{lrrrrrrr}
\hline \multicolumn{1}{c}{ Temperature and duration (days) of storage } \\
Sample & 1 & 3 & 7 & 14 & 28 & 56 & 84 \\
\hline 1 & 83 & 113 & 84 & 109 & 94 & 111 & 92 \\
2 & 106 & 93 & 90 & 98 & 105 & 105 & 111 \\
3 & 97 & 112 & 108 & 94 & 106 & 110 & 106 \\
\hline Average & 95.3 & 106.0 & 94.0 & 100.3 & 101.6 & 108.6 & 103.0 \\
\hline
\end{tabular}

Ta ble 1 (continued).

Temperature and duration (days) of storage

\begin{tabular}{crrrrrrrrr}
\hline \multicolumn{1}{c}{ Temperature and duration (days) of storage } & on \\
Sample & 1 & 3 & 7 & 14 & 28 & 56 & 84 & (unfrozen) \\
\hline 1 & 106 & 106 & 111 & 98 & 100 & 89 & 106 & 98 \\
2 & 124 & 100 & 116 & 87 & 91 & 104 & 98 & 100 \\
3 & 100 & 90 & 107 & 82 & 89 & 108 & 101 & 95 \\
\hline Average & 110.0 & 98.6 & 111.3 & 89.0 & 93.3 & 100.3 & 101.7 & 97.7 \\
\hline
\end{tabular}


The experiments were carried out with minced and thoroughly mixed muscle tissue from 2 rabbits dosed orally 9 weeks previously with $T$. spiralis larvae. The muscle tissue was divided in portions of $25 \mathrm{~g}$ each. Three such portions were examined in the fresh state, i.e. immediately following their preparation. The rest of the portions were packed separately in plastic bags and stored at $-20^{\circ} \mathrm{C}$ or $-70^{\circ} \mathrm{C}$. At different intervals (cf. Table 1) 3 samples from each group were picked out for examination. Prior to digestion the tissue was thawed by incubation at room temperature for $4 \mathrm{hrs}$. The numbers of larvae observed in the respective samples are specified in Table 1 . As will be seen, the average number of larvae was largely the same in all samples, whether frozen or not, and irrespectively of storage temperature and duration of storage.

Unlike larvae observed in the samples examined initially, larvae obtained from the frozen samples were more or less uncoiled. However, this in no way interfered with the visual recognition of the parasites.

It seems reasonable to conclude that the technique referred to above offers the same recovery rate for $\mathrm{T}$. spiralis larvae in frozen samples of muscle tissue as in comparable samples of unfrozen tissue.

\section{ACKNOWLEDGEMENT}

The author wishes to thank Mr. L. Eiersted for valuable technical assistance.

Sv. Aa. Henriksen

The State Veterinary Serum Laboratory, Copenhagen, Denmark.

\section{REFERENCES}

Dyer, W. G. \& V. A. Evje: A digestion-solvent technique for detecting dead trichinae. J. Parasit. 1971, 57, 1148-1149.

Henriksen, Sv. Aa.: A new technique for demonstration of Trichinella spiralis larvae in suspensions of digested muscle tissue. Acta vet. scand. $1978,19,466-468$.

Jackson, G.: Recovery of Trichinella spiralis larvae. Brit. vet. J. 1977, $133,318-319$.

(Received November 28, 1978).

Reprints may be requested from: Sv. Aa. Henriksen, The State Veterinary Serum Laboratory, Bülowsvej 27, DK-1870 Copenhagen V, Denmark. 